University of Nebraska - Lincoln

DigitalCommons@University of Nebraska - Lincoln

Faculty Publications: Department of

Entomology

Entomology, Department of

2020

\title{
Field efficacy of soil insecticides on pyrethroid-resistant western corn rootworms (Diabrotica virgifera virgifera LeConte)
}

\author{
Dariane Souza \\ University of Nebraska-Lincoln, dariane.souza@ufl.edu \\ Julie A. Peterson \\ University of Nebraska-Lincoln, julie.peterson@unl.edu \\ Robert Wright \\ University of Nebraska-Lincoln, rwright2@unl.edu \\ Lance Meinke \\ University of Nebraska-Lincoln, Imeinke1@unl.edu
}

Follow this and additional works at: https://digitalcommons.unl.edu/entomologyfacpub

Part of the Agriculture Commons, and the Entomology Commons

Souza, Dariane; Peterson, Julie A.; Wright, Robert; and Meinke, Lance, "Field efficacy of soil insecticides on pyrethroid-resistant western corn rootworms (Diabrotica virgifera virgifera LeConte)" (2020). Faculty Publications: Department of Entomology. 825.

https://digitalcommons.unl.edu/entomologyfacpub/825

This Article is brought to you for free and open access by the Entomology, Department of at DigitalCommons@University of Nebraska - Lincoln. It has been accepted for inclusion in Faculty Publications: Department of Entomology by an authorized administrator of DigitalCommons@University of Nebraska - Lincoln. 


\title{
Field efficacy of soil insecticides on pyrethroid-resistant western corn rootworms (Diabrotica virgifera virgifera LeConte)
}

\author{
Dariane Souza, ${ }^{1}$ Julie A. Peterson, ${ }^{2}$ \\ Robert J. Wright, ${ }^{1}$ and Lance J. Meinke ${ }^{1}$
}

1 University of Nebraska-Lincoln, Department of Entomology, Lincoln, NE, USA

2 University of Nebraska-Lincoln, Department of Entomology, West Central

Research \& Extension Center, North Platte, NE, USA

Corresponding author - D Souza, Department of Entomology and Nematology,

University of Florida, Gainesville, FL 32611, US; email dariane.souza@ufl.edu

\begin{abstract}
Background: Field-evolved pyrethroid resistance has been confirmed in western corn rootworm (WCR) populations collected from the United States (US) western Corn Belt. Resistance levels of WCR adults estimated in lab bioassays were confirmed to significantly reduce the efficacy of foliar-applied bifenthrin. The objective of the present study was to investigate the impact of WCR pyrethroid resistance levels on the performance of common soil-applied insecticide formulations (23.4\% tefluthrin, $17.15 \%$ bifenthrin, and $0.1 \%$ cyfluthrin $+2.0 \%$ tebupirimphos). Field trials were conducted in 2016 and 2017 in three Nebraska, US, counties (Saunders, Clay, and Keith) where distinct levels of WCR susceptibility topyrethroids (susceptible, moderately resistant, and highly resistant) had been previously reported in adult and larval bioassays.

Results: All soil insecticide treatments effectively protected maize roots from a pyrethroid-susceptible WCR population at Saunders. In contrast, the efficacy of bifenthrin and tefluthrin soil insecticides was significantly reduced at Clay and Keith,
\end{abstract}

Published in Pest Management Science 76 (2020), pp 827-833.

DOI 10.1002/ps.5586

Copyright (c) 2019 Society of Chemical Industry, www.soci.org. Published by Wiley. Used by permission.

Submitted 27 May 2019; revised 29 July 2019; accepted 15 August 2019; published 10 September 2019. 
where pyrethroid-resistant WCR populations were reported. At Keith, where an additional failure of the cyfluthrin+tebupirimphos soil insecticide was observed, WCR laboratory dose-response bioassays showed a consistent $\sim 5$-fold resistance level to the active ingredients bifenthrin, tefluthrin, and cyfluthrin.

Conclusion: The efficacy of common soil insecticides used in the US for WCR management was significantly reduced in populations exhibiting relatively low levels of WCR pyrethroid resistance. Using a multitactical approach to manage WCR within an integrated pest management framework may mitigate resistance evolution and prolong the usefulness of WCR insecticides within the system.

Keywords: Diabrotica virgifera virgifera, western corn rootworm, insecticide resistance, pyrethroid resistance, soil insecticides, resistance management

\section{Introduction}

The western corn rootworm (WCR), Diabrotica virgifera virgifera LeConte, (Coleoptera: Chrysomelidae) is a major pest of maize, Zea mays L., in the United States (US). ${ }^{1-3}$ Adult WCR may adversely affect maize pollination by severe silk clipping, ${ }^{4}$ although the most significant damage is caused by larvae feeding on maize roots. ${ }^{5,6}$ Yield loss from root injury or from subsequent plant lodging is highly variable and influenced by a number of biotic and abiotic factors, such as maize hybrid, environmental conditions, WCR density, and management practices. ${ }^{7-9}$ Root injury equivalent to one node of roots destroyed was associated with a 9.7-12.2\% yield reduction across hybrids tested under irrigation in Nebraska. ${ }^{9}$ For non-irrigated corn in Illinois, studies suggest that $15.2-17.9 \%$ yield loss may occur for each node of roots destroyed by WCR larvae. ${ }^{10,11}$ Current methods to protect maize from WCR injury include maize rotation with a nonhost crop, transgenic maize producing rootworm-specific Cry toxins, and soil- or foliar-applied insecticides. ${ }^{5,12,13}$ However, local socioeconomic conditions may dictate that some methods are not practical to implement. For example, in the US western Corn Belt, maize production under irrigation has often been more profitable than other available crops, which discourages the adoption of crop rotation. The demand for maize is high for livestock operations and ethanol production, leading to higher adoption of continuous maize (maize planted consecutively for two or more years). ${ }^{13-15}$ This can lead to build-up of WCR densities, making the annual management of this pest a considerable challenge. Furthermore, changes in pesticide regulations and 
field-evolved resistance to control tactics have limited the options to manage this important pest in the US.

In the late 1940s, organochlorine insecticides were introduced in the US and became very popular as soil broadcast applications for WCR larval control. ${ }^{5,16,17}$ The widespread use of this insecticide class, which remains active in the soil for long periods of time, selected for high levels of WCR resistance to the organochlorines aldrin and heptachlor in parts of the US Corn Belt. ${ }^{16,18,19}$ In the 1970 s, broadcast soil application of organochlorines was replaced by in-furrow or banded application of either carbamate or organophosphate insecticides that were less persistent in the field and primarily protected the root zone close to the plant stem from rootworm injury. ${ }^{20-23}$ The combination of insecticide chemistry and application placement provided a natural refuge as maize roots that grew outside of the treated zone produced WCR with little to no exposure to the insecticide, which helped maintain population susceptibility to soil-applied carbamates and organophosphates over time..$^{23,24}$

An alternative WCR management approach was also adopted in the western Corn Belt during the 1960s to 1990s, in which aerial application of either carbamate or organophosphate insecticides was used to suppress adult WCR populations. ${ }^{25-27}$ This was a stand-alone management strategy that targeted gravid WCR females to reduce egg density to a level that would not lead to economic loss in maize the following season. ${ }^{28}$ In Nebraska, aerial application of carbaryl or methyl parathion was common in continuous maize. By 1995, methyl parathion use reached approximately $30 \%$ of total insecticide use per weight ${ }^{29}$ and parts of Nebraska had been using the adult management strategy for up to 20-30 years. ${ }^{26,28}$ This practice placed annual selection pressure on adult WCR populations which led to field-evolved carbaryl and methyl parathion resistance ${ }^{26,30,31}$ and significantly impacted the performance of some soil insecticides. ${ }^{32}$ In 1996, the Food Quality Protection Act (FQPA) altered the regulation of pesticides and the US Environmental Protection Agency (EPA) canceled uses of a number of organophosphate and carbamate insecticides, leaving fewer options for WCR control. ${ }^{33}$

Soil insecticides were largely replaced in the 2000 s by genetically engineered maize expressing one or more rootworm-active proteins derived from Bacillus thuringiensis Berliner (Bt)., 2,17,34 WCR field-evolved resistance to commercially available $B t$ events has been documented 
in some areas of the US Corn Belt since 2009. ${ }^{13,35-40}$ Consequently, the use of soil- and foliar-applied insecticides has increased ${ }^{17}$ to complement $B t$ traits, to reduce high WCR densities, and to mitigate resistance. ${ }^{13}$ Because many carbamates and organophosphates had been removed from the market, there was a shift in insecticide class usage to pyrethroids such as bifenthrin. ${ }^{41,42}$

From 2002 to 2014, there was a 40\% increase in bifenthrin use on maize in Nebraska. ${ }^{29}$ This included soil and foliar applications for WCR control, and foliar applications targeting spider mites Tetranychus urticae Koch and western bean cutworm Striacosta albicosta Smith. ${ }^{42-44}$ The selection pressure imposed on maize pests from one or more aerial applications of bifenthrin per crop season led to field-evolved resistance of WCR to bifenthrin in some populations by $2015 .{ }^{42}$ Laboratory bioassays then revealed WCR cross-resistance to tefluthrin, a common soil insecticide active ingredient, and that resistance levels for both pyrethroids were higher for WCR adults than for larvae. ${ }^{45}$ The observed level of resistance was great enough to cause significant reductions in efficacy of formulated bifenthrin when resistant adult WCR were bioassayed at label rates under simulated aerial application conditions. ${ }^{15}$ The impact of larval pyrethroid resistance levels on the field performance of formulated pyrethroid soil insecticides has not been evaluated. In order to complement a larger project to characterize WCR pyrethroid resistance ${ }^{15,42,45}$ and to inform WCR management strategies, the present study was designed to (i) evaluate the efficacy of some commonly used formulated soil insecticides against WCR in fields with different levels of WCR pyrethroid resistance and (ii) estimate in the laboratory current susceptibility levels of WCR larvae to the soil insecticide active ingredients.

\section{Materials and Methods}

\subsection{Field performance of formulated soil insecticides}

In 2016 and 2017, replicated field trials were conducted in continuous maize to evaluate the performance of soil insecticides at three geographic locations in Nebraska, US, where different levels of WCR susceptibility to pyrethroids had been reported. ${ }^{42,45}$ A Saunders county field site was selected to test a pyrethroid-susceptible WCR 
population, whereas Clay and Keith county field sites were selected to test populations that exhibited moderate and high levels of WCR pyrethroid resistance, respectively. The Keith county locations in 2016 (Keith1) and 2017 (Keith2) were different commercial maize fields, 18 $\mathrm{km}$ apart, where annual soil and aerial bifenthrin applications had been made for 5 years prior to this study. The same locations in Saunders and Clay counties were used each year and are referred to in this study as Saunders and Clay, respectively. The Saunders site was at the University of Nebraska Eastern Nebraska Research and Extension Center, and the Clay site was at the University of Nebraska South Central Agricultural Lab. Saunders was surrounded by a large area of continuous maize that had not received insecticide applications for over 10 years. Bifenthrin had only been included previously at that location as a soil application in a few small-plot trials. At the Clay site, bifenthrin had only been used in small plot trials but was near commercial farms where soil- and foliar-applied bifenthrin had been used over the last decade.

The maize hybrid N65Z-3220 (Agrisure ${ }^{\circledR}$ Viptera ${ }^{T M}$, Syngenta Seeds Inc., Minnetonka, MN, US) was provided by the manufacturer and was used in all trials in both years. Seeds contained three $B t$ genes for controlling above-ground lepidopteran species (Cry1Ab/Cry1F/ Vip3A) and came treated with Avicta ${ }^{\circledR}$ Complete Corn 250 (Syngenta Crop Protection LLC, Greensboro, NC, US) that included thiamethoxam $(0.25 \mathrm{mg}$ a.i./seed). This rate of thiamethoxam provides protection against some seed or seedling feeding insects ${ }^{46}$ but provides little control of WCR larvae. ${ }^{12,47}$ Seeds were glyphosate tolerant and did not contain genetically engineered traits to control rootworms. Standard tillage, irrigation, nitrogenous fertilizer and weed control programs were used each year in all field locations.

Four treatments were tested: (i) untreated control; (ii) $1.17 \mathrm{~L} \mathrm{ha}^{-1}$ of liquid Capture LFR (bifenthrin 17.15\%, FMC, Philadelphia, PA, US), (iii) $0.73 \mathrm{~L} \mathrm{ha}^{-1}$ of liquid Force CS (tefluthrin $23.4 \%$, Syngenta Crop Protection LLC, Greensboro, NC, US), and (iv) $8.20 \mathrm{~kg} \mathrm{ha}^{-1}$ of granular Aztec 2.1G (cyfluthrin $0.1 \%+$ tebupirimphos $2.0 \%$, AMVAC, Newport Beach, CA, US). The fourth treatment was included as a positive control due to the presence of an organophosphate (OP) in the formulation. Liquid insecticides were prepared in tap water for a $46.77 \mathrm{~L} \mathrm{ha}^{-1}$ carrier volume rate. All insecticides were applied in-furrow at planting with four replicates randomized in four blocks. Each replicate consisted of 
a four-row plot $10 \mathrm{~m}$ long with $0.76 \mathrm{~m}$ row spacing $(74-79000$ seeds $\mathrm{ha}^{-1}$ ). When peak larval feeding was reached at each location (same WCR phenological period), five plants were randomly dug from the central two rows of each plot, labeled, and taken to a root-washing facility. Peak larval feeding was determined by preliminary larval sampling and presence of pupae/adults in the plots of each location. In 2016, roots were dug on July 20 (Saunders), July 15 (Clay), and July 27 (Keith1), whereas in 2017, roots were dug on July 18 (Saunders), July 12 (Clay), and July 25 (Keith2). Roots were washed and rated for rootworm injury using the $0-3$ node injury scale (NIS). ${ }^{48}$ In 2016, singleplant emergence cages ${ }^{49}$ were placed in all field locations to evaluate the impact of rootworm larval control obtained from each insecticide treatment on adult emergence. Three emergence cages were placed in the central two rows of each plot. Once WCR emergence started, adults were collected from cages and counted on a weekly basis until emergence had ended. Adult emergence periods in 2016 were June 28-August 22 (Saunders), June 27-August 11 (Clay), and July 6-October 10 (Keith1).

\subsection{Larval laboratory bioassays with insecticide active ingredients}

\subsection{Chemicals}

Analytical standards of bifenthrin, tefluthrin, cyfluthrin, and tebupirimphos were used, which were the active ingredients in the formulated soil insecticides tested in the field. Bifenthrin $98 \%$, cyfluthrin 99.2\%, and tebupirimphos $97 \%$ were obtained from Chem Service Inc. (West Chester, PA, US; Cat. Nos. N-11203/CAS 82657-04-3, N-11130/ CAS 68359-37-5, and N-13503/CAS 96182-53-5, respectively). Tefluthrin $\geq 95 \%$ was provided by Santa Cruz Biotechnology, Inc. (Dallas, TX, US; Cat. No. sc-236965/CAS 79538-32-2). All insecticides were dissolved in acetone $\geq 99.9 \%$ supplied by Sigma-Aldrich Corp. (St. Louis, MO, US; Cat. No. 650501/CAS 67-64-1) for stock solution preparation.

\subsubsection{WCR populations}

Four WCR populations were tested in the laboratory at the neonate larval stage ( $<36 \mathrm{~h}$ old). One pyrethroid-susceptible non-diapausing lab population (Lab) provided in 2017 by Crop Characteristics, Inc. (Farmington, MN, US) and three populations originally collected in 
August 2016 as adults from cornfields in Nebraska, US were used. At least $600 \mathrm{WCR}$ adults were collected from each field population. The population from Saunders was pyrethroid-susceptible, whereas populations from Keith1 and Keith2 were pyrethroid-resistant. ${ }^{15}$ Adults collected in 2016 were taken to the Department of Entomology at the University of Nebraska-Lincoln, Lincoln, NE, US and maintained there under standard rearing procedures. ${ }^{13}$ Eggs obtained from field-collected populations were held for 1 month at $25 \pm 1 \circ \mathrm{C}$ then maintained in a growth chamber at $8 \pm 1 \circ \mathrm{C}$ in diapause for 4-5 months before transferring to $25 \pm 1 \circ \mathrm{C}$ to facilitate post-diapause egg development. All field collections were allowed by the property owners.

\subsubsection{Bioassays}

In 2017, dose-response bioassays were performed with insecticide analytical standards to estimate the susceptibility of WCR larvae to the active ingredients of commercial soil insecticides. Filter papers obtained from Thermo Fisher Scientific Inc. (Waltham, MA, US) (Whatman $^{\text {TM }}$ grade 1, circles $42.5 \mathrm{~mm}$, Cat. No. 1001-042), were placed inside sterile Petri dishes purchased from VWR International (Radnor, PA, US) $(9.0 \mathrm{~mm}$ height $\times 50.0 \mathrm{~mm}$ diameter; Pall Corporation, Port Washington, NY, US; Cat. No. 25388-606) and treated with increasing concentrations of bifenthrin, tefluthrin, cyfluthrin, and tebupirimphos following methods described in previous research. ${ }^{42,45,50}$ For a negative control, filter papers were treated with purified water only. Insecticide stock solutions prepared in acetone were adjusted with purified water into five to eight concentrations considering the solubility parameters of each compound. The number of insecticide concentrations used to test each population varied depending on the number of WCR larvae available. A volume of $150 \mu \mathrm{L}$ insecticide solution was homogeneously applied on each filter paper with a pipette and each concentration was replicated three times. Treated filter papers were allowed to dry at room temperature for $15 \mathrm{~min}$ to prevent condensation on the Petri dishes once closed. A group of 20 WCR larvae were then carefully transferred to each Petri dish using a fine camel hair paintbrush. Petri dishes were then closed and maintained in the dark at a temperature of $23 \pm 1 \circ \mathrm{C}$. Larval mortality was recorded at 24 $\mathrm{h}$ after infestation. Larvae that did not respond to gentle prodding or were unable to move around the filter paper area consistently were considered dead. 


\subsection{Statistical analysis}

Node injury scores recorded from plants dug from each plot followed a continuous distribution within the restricted interval of $[0,3]$. Continuous proportion data that do not extend to +/- infinity (like a Normal distribution) and are restricted by a specific positive interval may fit a Beta-binomial distribution with continuous values within the restricted interval of $[0,1] . .^{51,52}$ Thus, $0-3$ root rating values obtained were divided by three to obtain a $0-1$ proportional injury and were analyzed with a Beta-binomial distribution. To estimate soil treatment effects on adult WCR emergence in 2016, the total number of beetles emerged from each plot was analyzed with a Negative-binomial distribution. Emergence count data are discrete integer values that show over dispersion (variance greater than the mean) following the aforementioned distribution premises. ${ }^{52-54}$ Root ratings and adult emergence data were evaluated using their correspondent distribution logit link functions with a generalized mixed model in SAS 9.4 software (SAS Institute, Cary, NC, US). A randomized complete block experimental design (RCBD) with 3 $\times 4$ factorial treatment design was used. The three field locations and the four soil treatments were adopted as fixed factors in the statistical model. Random blocks were nested within each field location. Multiple comparison of treatment means was performed using Fisher's least significant difference procedure at significance level $\alpha=0.05$. A separate analysis was conducted per year because different Keith locations were used each year and WCR larval pressure was variable per site and year.

To evaluate the susceptibility of WCR larvae to insecticide active ingredients in the laboratory, the $\mathrm{LC}_{50}$ values of different populations were estimated by probit analysis. Mortality data for each insecticide concentration tested was analyzed using the POLOPlus-PC software algorithm (LeOra Software LLC) that corrects for natural control mortality using Abbot's formula ${ }^{55}$ and conducts analyses with a probit function and Normal distribution. ${ }^{56-59}$ The probit procedure also performed a Pearson goodness-of-fit test between observed data and expected regression lines, and estimated resistance ratios $\left(R_{50}\right)$ with correspondent $95 \%$ confidence intervals between $\mathrm{LC}_{50}$ values of field and lab populations. When $\mathrm{RR}_{50}$ confidence intervals between pyrethroid-susceptible (Saunders) and pyrethroid-resistant (Keith1 and Keith2) field populations overlapped, a test of equality of slopes and intercepts of regression lines was performed using the same software, and the statistical significance estimated at $\alpha=0.05 .{ }^{59}$ 


\section{Results}

\subsection{Field performance of formulated soil insecticides}

A significant treatment by field interaction effect on root injury each year indicated that insecticide treatments performed differently depending on field location (2016: $F_{6,27}=4.60, P=0.0024 ; 2017: F_{6,27}=5.33$, $P=0.0010)$. Overall, significantly lower mean root injury was observed in both years for all soil insecticides tested at Saunders and Clay relative to untreated control plots (Fig. 1). Conversely, mean root injury in each soil insecticide treatment at Keith1 and Keith2 was not significantly different from mean injury in respective untreated control treatments (Fig. 1). Root rating means of all treatments tested at Keith1 and Keith2 were consistently within the $0.8-1.7$ range.

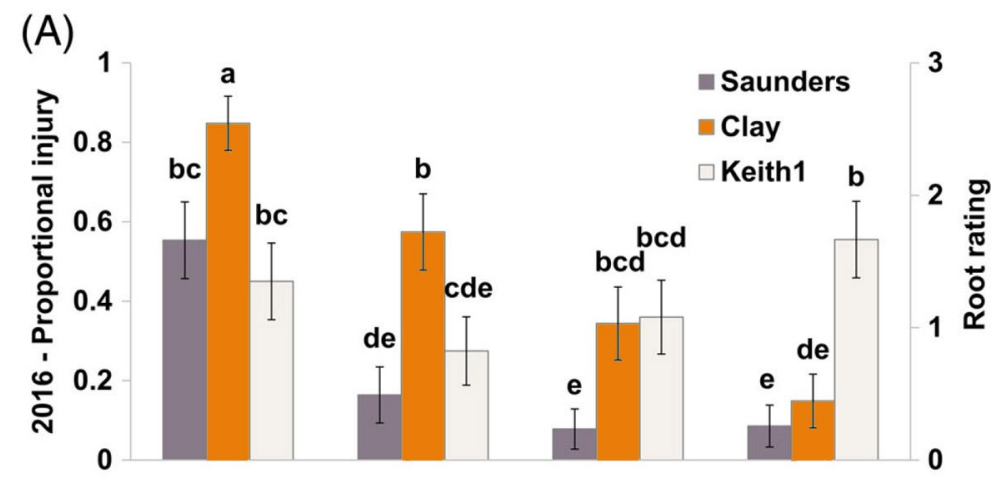

(B)

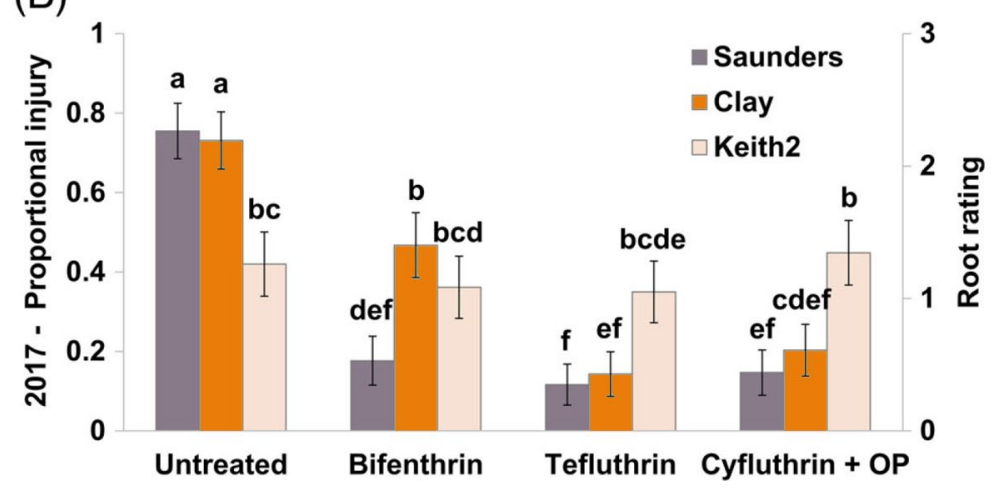

Figure 1. Field performance of commercial soil insecticides on larvae of three WCR populations. Graph presents treatment by field interaction effects on proportional root injury means \pm SE evaluated at three different Nebraska, US field locations in (A) $2016\left(F_{6,27}=4.60, P=0.0024\right)$ and (B) $2017\left(F_{6,27}=5.33, P=0.0010\right)$. Saunders was a pyrethroid-susceptible population, whereas Clay and Keith populations exhibited moderate and high levels of pyrethroid-resistance, respectively. Means \pm SE across treatments and field locations followed by the same letter are not statistically different (Fisher's LSD test, $P>0.05$ ). 
At the Clay location, root injury in plots treated with bifenthrin soil insecticide was significantly greater than injury in cyfluthrin $+O P$ treated plots each year (i.e. $43 \%$ and $26 \%$ greater in $2016(P=0.0038)$ and 2017 ( $P=0.0212)$, respectively). Mean root injury in the bifenthrin treatment was significantly greater than mean injury in the tefluthrin treatment during 2017 ( $P=0.0057)$ but not during $2016(P=0.0937)$. Also, mean injury in the tefluthrin treatment was not significantly greater than mean injury in the cyfluthrin+OP treatment in either year (2016: $P=0.1047 ; 2017: P=0.4866$ ).

The analysis of mean WCR adult counts collected in single-plant emergence cages during 2016 (Fig. 2) indicated no significant treatment by field interaction effect $\left(F_{6,27}=0.83, P=0.5601\right)$ or overall insecticide treatment effect $\left(F_{3,33}=1.87, P=0.1540\right)$ on beetle emergence. Significantly higher mean WCR adult emergence per plot was recorded at Saunders than Clay and Keith1 (Fig. 2).

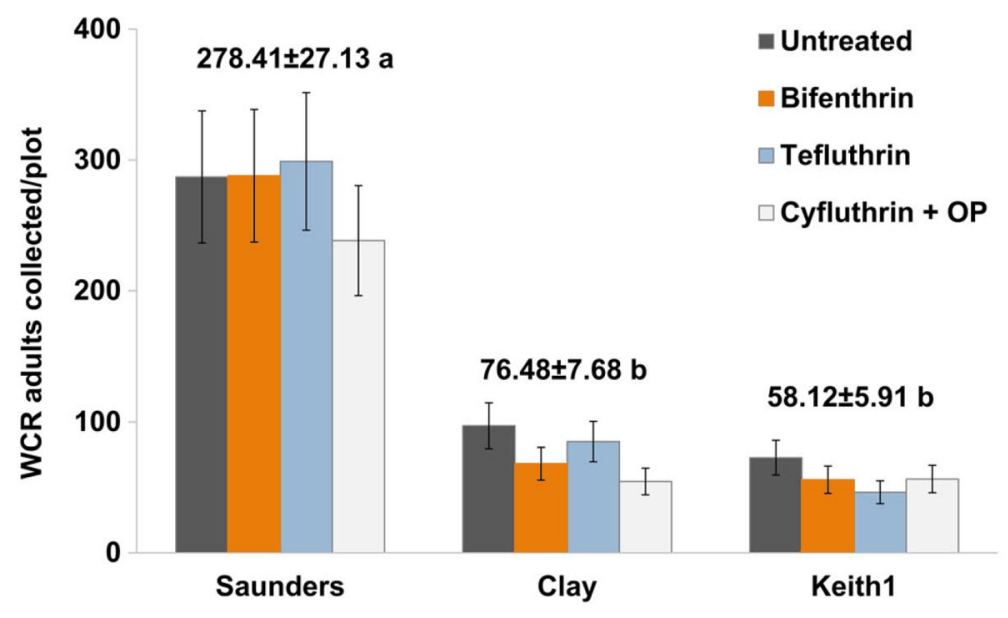

Figure 2. 2016 WCR adult emergence at three Nebraska, US field locations where soil insecticide trials were conducted. Graph presents mean number of beetles \pm SE collected from three single-plant emergence cages per plot for treatment by field combinations (bars) and for field locations across treatments (above bars). The effects of treatment by field interaction $\left(F_{6,27}=0.83, P=0.5601\right)$ and overall insecticide treatment $\left(F_{3,33}=1.87, P=0.1540\right)$ were not significant on adult emergence. Mean adult emergence was significantly greater at Saunders than at the other two sites $\left(F_{2,9}=71.61, P<0.0001\right)$. Field location overall means followed by the same letter were not statistically different (Fisher's LSD test, $P>0.05$ ). 


\subsection{Larval laboratory bioassays with insecticide active ingredients}

Probit analysis of concentration-mortality regressions effectively estimated susceptibility levels of WCR larvae to soil insecticide active ingredients (Table 1). Populations from Keith1 and Figure 2. 2016 WCR adult emergence at three Nebraska, US field locations where soil insecticide trials were conducted. Graph presents mean number of beetles \pm SE collected from three single-plant emergence cages per plot for treatment by field combinations (bars) and for field locations across treatments (above bars). The effects of treatment by field interaction $\left(F_{6,27}=0.83, P=0.5601\right)$ and overall insecticide treatment $\left(F_{3,33}=\right.$ $1.87, P=0.1540$ ) were not significant on adult emergence. Mean adult emergence was significantly greater at Saunders than at the other two sites $\left(F_{2,9}=71.61, P<0.0001\right)$. Field location overall means followed by the same letter were not statistically different (Fisher's LSD test, $P>$ 0.05). Keith2 consistently exhibited reduced susceptibility to all three

Table 1. WCR larval susceptibility of pyrethroid-susceptible (Lab, Saunders) and pyrethroid-resistant (Keith1, Keith2) populations estimated in 2017 for the active ingredients of commercial soil insecticides.

\begin{tabular}{lrrrrrr} 
Insecticide & Population & $N^{a}$ & Slope $\pm S E$ & $L C_{50}(95 \% C l)^{b}$ & $X^{2}(d f)$ & $R R_{50}(95 \% C l)^{c}$ \\
\hline Bifenthrin & Lab & 241 & $3.98 \pm 0.58$ & $0.88(0.76-0.98)$ & $0.32(2)$ & \\
& Saunders & 303 & $3.84 \pm 0.51$ & $2.78(2.32-3.21)$ & $1.72(3)$ & $3.13(2.54-3.86)$ \\
& Keith1 & 366 & $1.95 \pm 0.19$ & $4.12(3.29-5.04)$ & $1.44(4)$ & $4.64(3.60-5.97)$ \\
Tefluthrin & Keith2 & 634 & $1.57 \pm 0.17$ & $3.82(2.87-4.89)$ & $1.52(4)$ & $4.30(3.20-5.79)$ \\
& Lab & 302 & $9.74 \pm 1.24$ & $0.54(0.50-0.57)$ & $2.92(3)$ & \\
& Saunders & 240 & $6.86 \pm 0.76$ & $1.18(1.10-1.27)$ & $1.93(2)$ & $2.18(1.98-2.41)$ \\
Cyfluthrin & Keith1 & 420 & $10.42 \pm 1.96$ & $2.92(2.10-3.25)$ & $7.46(5)$ & $5.41(4.81-6.09)$ \\
& Keith2 & 421 & $5.04 \pm 0.59$ & $2.21(1.86-2.49)$ & $6.20(5)$ & $4.10(3.65-4.61)$ \\
& Lab & 300 & $2.35 \pm 0.29$ & $3.31(2.65-4.06)$ & $2.34(3)$ & \\
Tebupirimphos & Saunders & 298 & $1.21 \pm 0.19$ & $2.29(1.52-3.11)$ & $1.10(3)$ & $0.68(0.45-1.03)$ \\
& Keith1 & 301 & $1.28 \pm 0.15$ & $19.42(13.43-26.79)$ & $0.66(3)$ & $5.78(3.85-8.68)$ \\
& Keith2 & 243 & $1.13 \pm 0.20$ & $14.11(7.42-21.0)$ & $1.13(2)$ & $4.20(2.47-7.14)$ \\
& Lab & 423 & $11.32 \pm 1.11$ & $0.44(0.42-0.46)$ & $4.14(5)$ & \\
& Saunders & 429 & $9.38 \pm 0.80$ & $0.38(0.36-0.40)$ & $4.22(5)$ & $0.86(0.81-0.92)$ \\
& Keith1 & 241 & $17.50 \pm 2.16$ & $0.52(0.50-0.53)$ & $1.47(5)$ & $1.17(1.11-1.23)$ \\
& Keith2 & 240 & $7.66 \pm 1.01$ & $0.66(0.60-0.72)$ & $1.38(5)$ & $1.51(1.36-1.67)$
\end{tabular}

a. Number of insects tested.

b. $\mathrm{ng} \mathrm{cm}^{-2}$.

c. Resistance ratios relative to a pyrethroid-susceptible laboratory population (Lab). 
pyrethroid insecticides tested. Resistance ratios $\left(R R_{50}\right)$ of Keith populations for bifenthrin, tefluthrin, and cyfluthrin were all near 5 -fold. Although $R_{50}$ confidence intervals of Saunders overlapped with those of Keith populations for bifenthrin, they were found to be significantly different in the test of equality of slopes and intercepts (Keith1: $\chi^{2}$ (d.f.)

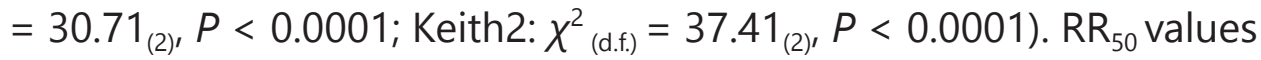
of Keith populations estimated for tebupirimphos were all $<2$-fold and their confidence intervals did not overlap with those estimated for Saunders and Lab populations.

\section{Discussion}

This study confirms that a relatively low level of WCR pyrethroid resistance detected in laboratory bioassays ${ }^{15,42,45}$ significantly reduces the performance of formulated soil-applied pyrethroid products in the field. A study that analyzed over a decade of research at multiple US maize-producing sites indicated that nearly $86 \%$ less root injury occurred in conventional maize when a soil insecticide was applied in addition to a standard low-rate seed treatment. ${ }^{60}$ Similar results were observed at Saunders in this study, as treatments tested on the WCR pyrethroid-susceptible population provided $70-86 \%$ less root injury than observed in untreated control plots. In contrast, the performance of commercial pyrethroids bifenthrin and tefluthrin was significantly reduced at Clay and Keith sites, which were previously confirmed ${ }^{15,42}$ to contain pyrethroid-resistant WCR populations. Particularly at Keith1 and Keith2, the range of mean root injury ratings consistently observed for all treatments tested was at a level that is often associated with significant yield loss. ${ }^{7-11,48}$

The results presented here confirm the $\sim 5$-fold pyrethroid crossresistance between bifenthrin and tefluthrin previously detected in WCR larvae, ${ }^{42,45}$ and also report a similar level of WCR resistance to cyfluthrin, which is structurally classified as a Type II pyrethroid by the presence of a $\alpha$-cyano group. ${ }^{61,62}$ Cross-resistance between Type I and Type II pyrethroids does not always occur. ${ }^{63}$ When it does, it is commonly associated with target site mutations in the voltage-gated sodium channels ( $k d r$ mutations), ${ }^{64-67}$ which was identified previously as a possible mechanism of WCR pyrethroid resistance. ${ }^{45}$ 
The control failure of cyfluthrin+tebupirimphos soil insecticide formulation consistently observed in different Keith fields during the 2-year study was unexpected and the reasons for that failure are unclear. Additional experiments are needed to further investigate the performance of tebupirimphos in a mixture with cyfluthrin on pyrethroid-resistant WCR populations. Cyfluthrin cross-resistance observed in larval bioassays for pyrethroid-resistant Keith populations could be a factor contributing to the observed field efficacy reduction. Cross-resistance and synergism studies suggested enhanced metabolism as part of the WCR pyrethroid resistance mechanism, ${ }^{45}$ which could mutually affect the performance of structurally related insecticides, such as pyrethroids and organophosphates. A laboratory investigation of both Keith populations revealed a decreased susceptibility of pyrethroid-resistant WCR adults to the organophosphate dimethoate. ${ }^{15}$ Examination of the activity of the main detoxification enzymes in pyrethroid-resistant WCR may clarify the magnitude of enhanced metabolism possibly contributing to the resistance trait observed.

Another factor, along with potential resistance, that could have contributed to poor tebupirimphos efficacy at the Keith locations was soil $\mathrm{pH}$. Soil $\mathrm{pH}$ at Clay and Saunders was generally in the 6.3-6.8 range while $\mathrm{pH}$ was highly alkaline in Keith County (7.8-8.4). High pH can expedite degradation of organophosphate insecticides, ${ }^{22,68,69}$ which may reduce the actual exposure dose when WCR larvae are present. However, documentation of a cyfluthrin+tebupirimphos formulation failure in southwestern Nebraska is unusual, as this product has been effectively used as a positive control in previous field trials, including locations where soil $\mathrm{pH}$ is high. ${ }^{70}$ Additional research on the persistence of tebupirimphos would be needed to clarify if $\mathrm{pH}$ contributed to the poor efficacy observed at Keith1 and Keith2.

Although there was no significant effect of soil insecticides on adult WCR emergence, the highest emergence averaged over all treatments was observed at Saunders, where insecticide treatments significantly reduced root injury. The adult emergence data collected supports previous studies ${ }^{24,71}$ that showed an inconsistent effect of soil insecticides on adult emergence. In-furrow or banded placement of soil insecticides was designed to protect the main maize root mass from larval injury and prevent lodging, but, because of the built-in untreated refuge between rows, a considerable number of larvae may 
complete development to the adult stage. ${ }^{71}$ Previous investigations suggest that adult emergence is reduced only when a high larval population is reached and density dependent mortality occurs. ${ }^{72}$ The resistance levels present at Clay and both Keith sites may have led to greater larval survival and more density-dependent larval mortality than present at the Saunders site, leading to greater adult emergence at Saunders. ${ }^{72-74}$ Therefore, although excellent root protection was provided at Saunders, soil insecticide treatments did not manage the local WCR population.

This study is one of only two known cases where the efficacy of WCR soil insecticide active ingredients in lab bioassays and/or formulated products applied in-furrow or banded over the row at planting was reduced by WCR resistance. In each case, resistance appeared to evolve by selection for resistance in adults with foliar applications, leading to reduced efficacy of one or more soil insecticides targeting WCR larvae. In this study, adult selection with pyrethroids adversely affected larval control with pyrethroids and possibly an organophosphate. In a previous study, adult selection with the organophosphate methyl parathion negatively impacted larval control with the pyrethroid tefluthrin and organophosphates methyl parathion and carbofuran..$^{32}$ In areas of the US Corn Belt where foliar applications have not been commonly used, WCR resistance evolution has never been documented to soil insecticides applied in-furrow or banded over the row. Insecticide resistance evolution attributed to direct selection of WCR larvae has only been documented when the persistent soil insecticides in the organochlorine class were broadcast-applied during the 1950 s and 1960s. ${ }^{16,18,19}$

In conclusion, this study revealed that relatively low levels of WCR pyrethroid resistance estimated in the lab may be sufficient to cause control failure of commonly used pyrethroid soil insecticides in the field. The reduced field performance of soil applied bifenthrin, tefluthrin, and possibly cyfluthrin in southwestern Nebraska significantly restricts the insecticide options left there to protect maize roots from pyrethroid-resistant WCR. ${ }^{42}$ Rotation of crops, plant-incorporated rootworm-active traits, and insecticide modes of action within an IPM framework is the current recommendation to manage pyrethroid-resistant WCR populations. Since evidence collected to date supports the conclusion that adult WCR selection is impacting resistance levels 
expressed in the larval stage, ${ }^{15,42,45}$ foliar applications of insecticides on maize should be used wisely ${ }^{15,75}$ to prolong the efficacy of soil insecticide compounds available and to delay the evolution of WCR insecticide resistance.

Acknowledgments - The authors would like to thank the Brazilian Ministry of Education Foundation CAPES for the financial support of the doctorate student involved in this study (proc No. 013398/2013-00) and Monsanto for the project funding (Corn Rootworm Knowledge Grant, No. 69292). The authors also would like to thank James Brown, Jeffrey Golus, Kayla Mollet, Terry DeVries, summers workers, and crop consultants for their valuable assistance, and growers who allowed beetle collections and field trials on their land.

\section{References}

1 Gray ME, Sappington TW, Miller NJ, Moeser J and Bohn MO, Adaptation and invasiveness of western corn rootworm: intensifying research on a worsening pest. Annu Rev Entomol 54:303-321 (2009).

2 Andow DA, Pueppke SG, Schaafsma AW, Gassmann AJ, Sappington TW, Meinke LJ et al., Early detection and mitigation of resistance to Bt maize by western corn rootworm (Coleoptera: Chrysomelidae). J Econ Entomol 109:1-12 (2016).

3 Wechsler S and Smith D, Has resistance taken root in U.S. corn fields? Demand for insect control. Am J Agric Econ 100:1136-1150 (2018).

4 Meinke LJ, Adult Corn Rootworm Suppression: Corn Rootworm Management in the Transgenic Era, APS Plant Management Network, 2014. http://www. plantmanagementnetwork.org/edcenter/seminars/corn/AdultRootworm/ [20 May 2019].

5 Levine $\mathrm{E}$ and Oloumi-Sadeghi $\mathrm{H}$, Management of diabroticite rootworms in corn. Annu Rev Entomol 36:229-255 (1991).

6 Hou X, Meinke LJ and Arkebauer TJ, Soil moisture and larval western corn rootworm injury: influence on gas exchange parameters in corn. Agron J 89:709 (1997).

7 Gray ME and Steffey KL, Corn rootworm (Coleoptera: Chrysomelidae) larval injury and root compensation of 12 maize hybrids: an assessment of the economic injury index. J Econ Entomol 91:723-740 (1998).

8 Sutter GR, Branson TF, Fisher JR, Elliott NC and Jackson JJ, Effect of insecticide treatments on root damage ratings of maize in controlled infestations of western corn rootworms (Coleoptera: Chrysomelidae). J Econ Entomol 82:17921798 (1989).

9 Urías-López MA and Meinke LJ, Influence of western corn rootworm (Coleoptera: Chrysomelidae) larval injury on yield of different types of maize. $J$ Econ Entomol 94:106-111 (2001). 
10 Dun Z, Mitchell PD and Agosti M, Estimating Diabrotica virgifera virgifera damage functions with field trial data: applying an unbalanced nested error component model. J Appl Entomol 134:409-419 (2010).

11 Tinsley NA, Estes RE and Gray ME, Validation of a nested error component model to estimate damage caused by corn rootworm larvae. J Appl Entomol 137:161-169 (2013).

12 Petzold-Maxwell JL, Meinke LJ, Gray ME, Estes RE and Gassmann AJ, Effect of Bt-maize and soil insecticides on yield, injury, and rootworm survival: implications for resistance management. J Econ Entomol 106:1941-1951 (2013).

13 Wangila DS, Gassmann AJ, Petzold-Maxwell JL, French BW and Meinke LJ, Susceptibility of Nebraska western corn rootworm (Coleoptera: Chrysomelidae) populations to Bt corn events. J Econ Entomol 108:742-751 (2015).

14 Reinders JD, Hitt BD, Stroup WW, French BW and Meinke LJ, Spatial variation in western corn rootworm (Coleoptera: Chrysomelidae) susceptibility to Cry3 toxins in Nebraska. PLoS One 13:e0208266 (2018).

15 Souza D, Vieira BC, Fritz BK, Hoffmann WC, Peterson JA, Kruger GR et al., Western corn rootworm pyrethroid resistance confirmed by aerial application simulations of commercial insecticides. Sci Rep 9:6713 (2019).

16 Ball HJ and Weekman GT, Differential resistance of corn rootworms to insecticides in Nebraska and adjoining states. J Econ Entomol 56:553-555 (1963).

17 Fernandez-Cornejo J, Nehring RF, Osteen C, Wechsler S, Martin A and Vialou A, Pesticide use in U.S. agriculture: 21 selected crops, 1960-2008. EIB-124, US Department of Agriculture, Economic Research Service (2014). https://www.ers. usda.gov/webdocs/publications/43854/46734 eib124.pdf [20 May 2019].

18 Ball HJ and Weekman GT, Insecticide resistance in the adult western corn rootworm in Nebraska. J Econ Entomol 55:439-441 (1962).

19 Chio H, Chang C-S, Metcalf RL and Shaw J, Susceptibility of four species of Diabrotica to insecticides. J Econ Entomol 71:389-393 (1978).

20 Sutter GR, Branson TF, Fisher JR and Elliott NC, Effect of insecticides on survival, development, fecundity, and sex ratio in controlled infestations of western corn rootworm (Coleoptera: Chrysomelidae). J Econ Entomol 84:19051912 (1991).

21 Mayo ZB, Field evaluation of insecticides for control of larvae of corn rootworms, in Methods for the Study of Pest Diabrotica. Springer, New York, pp. 183-203 (1986).

22 Felsot AS, Enhanced biodegradation of insecticides in soil: implications for agroecosystems. Annu Rev Entomol 34:453-476 (1989).

23 Parimi S, Meinke LJ, Wade French B, Chandler LD and Siegfried BD, Stability and persistence of aldrin and methyl-parathion resistance in western corn rootworm populations (Coleoptera: Chrysomelidae). Crop Prot 25:269-274 (2006).

24 Gray ME, Felsot AS, Steffey KL and Levine E, Planting time application of soil insecticides and western corn rootworm (Coleoptera: Chrysomelidae) emergence: implications for long-term management programs. J Econ Entomol 85:544-553 (1992). 
25 Van Rozen K and Ester A, Chemical control of Diabrotica virgifera virgifera LeConte. J Appl Entomol 134:376-384 (2010).

26 Meinke LJ, Siegfried BD, Wright RJ and Chandler LD, Adult susceptibility of Nebraska western corn rootworm (Coleoptera: Chrysomelidae) populations to selected insecticides. J Econ Entomol 91:594-600 (1998).

27 Pruess KP, Witkowski JF and Raun ES, Population suppression of western corn rootworm by adult control with ULV malathion. J Econ Entomol 67:651-655 (1974).

28 Meinke LJ, Adult Corn Rootworm Management, Univ Neb Agric Res Div Misc Publ 63-C. University of Nebraska-Lincoln, Lincoln NE (1995).

29 NASS-USDA, USDA/NASS QuickStats Ad-hoc Query Tool. https://quickstats. nass.usda.gov/ [20 May 2019].

30 Scharf ME, Meinke LJ, Siegfried BD, Wright RJ and Chandler LD, Carbaryl susceptibility, diagnostic concentration determination, and synergism for U.S. populations of western corn rootworm (Coleoptera: Chrysomelidae). J Econ Entomol 92:33-39 (1999).

31 Zhu KY, Wilde GE, Higgins RA, Sloderbeck PE, Buschman LL, Shufran RA et al., Evidence of evolving carbaryl resistance in western corn rootworm (Coleoptera: Chrysomelidae) in area-wide-managed cornfields in North Central Kansas. J Econ Entomol 94:929-934 (2001).

32 Wright RJ, Scharf ME, Meinke LJ, Zhou X, Siegfried BD and Chandler LD, Larval susceptibility of an insecticide-resistant western corn rootworm (Coleoptera: Chrysomelidae) population to soil insecticides: laboratory bioassays, assays of detoxification enzymes, and field performance. J Econ Entomol 93:7-13 (2000).

33 Zager E, Tarplee B and Wooge W, EPA's pioneering response to FQPA mandate: assessing the cumulative effects of pesticides. Pestic Outlook 14:133-135 (2003).

34 Tabashnik BE, Delaying insect resistance to transgenic crops. Proc Natl Acad Sci USA 105:19029-19030 (2008).

35 Gassmann AJ, Petzold-Maxwell JL, Keweshan RS and Dunbar MW, Fieldevolved resistance to Bt maize by western corn rootworm. PLoS One 6:e22629 (2011).

36 Gassmann AJ, Petzold-Maxwell JL, Clifton EH, Dunbar MW, Hoffmann AM, Ingber DA et al., Field-evolved resistance by western corn rootworm to multiple Bacillus thuringiensis toxins in transgenic maize. Proc Natl Acad Sci USA 111:5141-5146 (2014).

37 Gassmann AJ, Shrestha RB, Jakka SRK, Dunbar MW, Clifton EH, Paolino AR et al., Evidence of resistance to Cry34/35Ab1 corn by western corn rootworm (Coleoptera: Chrysomelidae): root injury in the field and larval survival in plantbased bioassays. J Econ Entomol 109:1872-1880 (2016).

38 Jakka SRK, Shrestha RB and Gassmann AJ, Broad-spectrum resistance to Bacillus thuringiensis toxins by western corn rootworm (Diabrotica virgifera virgifera). Sci Rep 6:27860 (2016).

39 Ludwick DC, Meihls LN, Ostlie KR, Potter BD, French L and Hibbard BE, Minnesota field population of western corn rootworm (Coleoptera: Chrysomelidae) shows incomplete resistance to Cry34Ab1/ Cry35Ab1 and Cry3Bb1. J Appl Entomol 141:28-40 (2017). 
40 Zukoff SN, Ostlie KR, Potter B, Meihls LN, Zukoff AL, French L et al., Multiple assays indicate varying levels of cross resistance in Cry3Bb1- selected field populations of the western corn rootworm to mCry3A, eCry3.1Ab, and Cry34/35Ab1. J Econ Entomol 109:1387-1398 (2016).

41 Atwood D and Paisley-Jones C, US EPA-Pesticides Industry Sales and Usage 2008-2012 Market Estimates, 2017. https://www.epa.gov/sites/production/ files/2017-01/documents/pesticides-industry-sales-usage-2016 0.pdf [15 May 2019]

42 Pereira AE, Wang H, Zukoff SN, Meinke LJ, French BW and Siegfried BD, Evidence of field-evolved resistance to bifenthrin in western corn rootworm (Diabrotica virgifera virgifera LeConte) populations in western Nebraska and Kansas. PLoS One 10:e0142299 (2015).

43 Archibald WR, Bradshaw JD, Golick DA, Wright RJ and Peterson JA, Nebraska growers' and crop consultants' knowledge and implementation of integrated pest management of western bean cutworm. J Integr Pest Manage 9:1-7 (2017).

44 Michel AP, Krupke $\mathrm{CH}$, Baute TS and Difonzo CD, Ecology and management of the western bean cutworm(Lepidoptera:Noctuidae) in corn and dry beans. $J$ Integr Pest Manage 1:A1-A10 (2010).

45 Pereira AE, Souza D, Zukoff SN, Meinke LJ and Siegfried BD, Cross-resistance and synergism bioassays suggest multiple mechanisms of pyrethroid resistance in western corn rootworm populations. PLoS One 12:e0179311 (2017).

46 Maienfisch P, Angst M, Brandl F, Fischer W, Hofer D, Kayser H et al., Chemistry and biology of thiamethoxam: a second generation neonicotinoid. Pest Manag Sci 57:906-913 (2001).

47 Obopile M, Hammond RB and Thomison PR, Interaction among planting dates, transgenic maize, seed treatment, corn rootworm damage and grain yield. J Appl Entomol 137:45-55 (2013).

48 Oleson JD, Park Y-L, Nowatzki TM and Tollefson JJ, Node-injury scale to evaluate root injury by corn rootworms (Coleoptera: Chrysomelidae). J Econ Entomol 98:1-8 (2005).

49 Pierce CMF and Gray ME, Population dynamics of a western corn rootworm (Coleoptera: Chrysomelidae) variant in east central Illinois commercial maize and soybean fields. J Econ Entomol 100: 1104-1115 (2007).

50 Magalhaes LC, French BW, Hunt TE and Siegfried BD, Baseline susceptibility of western corn rootworm (Coleoptera: Chrysomelidae) to clothianidin. J Appl Entomol 131:251-255 (2007).

51 Ferrari S and Cribari-Neto F, Beta regression for modelling rates and proportions. J Appl Stat 31:799-815 (2004).

52 Stroup WW, Rethinking the analysis of non-normal data in plant and soil science. Agron J 107:811-827 (2015).

53 Bliss $\mathrm{Cl}$ and Fisher RA, Fitting the negative binomial distribution to biological data. Biometrics 9:176-200 (1953).

54 Tripathi RC, Negative binomial distribution, in Encyclopedia of Statistical Sciences, ed. by Kotz S, Read CB, Balakrishnan N, Vidakovic B and Johnson NL. John Wiley and Sons, Hoboken, NJ, Vol 8, 2nd edition, pp. 5413-5420 (2006). 
55 Abbott WS, A method of computing the effectiveness of an insecticide. J Econ Entomol 18:265-267 (1925).

56 Finney DJ, Probit analysis, 3rd edn. Cambridge University Press, Cambridge (1971).

57 Russell RM and Robertson JL, Programming probit analysis. Bull Entomol Soc Am 25:191-193 (1979).

58 LeOra Software, Polo-PC: A User's Guide to Probit or Logit Analysis. LeOra Software, Berkeley (1987).

59 Robertson JL, Savin N, Preisler HK and Russell RM, Bioassays with Arthropods, 2nd edn. CRC Press, Boca Raton, FL (2007).

60 Tinsley NA, Mitchell PD, Wright RJ, Meinke LJ, Estes RE and Gray ME, Estimation of efficacy functions for products used to manage corn rootworm larval injury. J Appl Entomol 140:414-425 (2015).

61 Soderlund DM, Molecular mechanisms of pyrethroid insecticide neurotoxicity: recent advances. Arch Toxicol 86:165-181 (2011).

62 Verschoyle RD and Aldridge WN, Structure-activity relationships of some pyrethroids in rats. Arch Toxicol 45:325-329 (1980).

$63 \mathrm{Hu}$ Z, Du Y, Nomura Y and Dong K, A sodium channel mutation identified in Aedes aegypti selectively reduces cockroach sodium channel sensitivity to type I, but not type II pyrethroids. Insect Biochem Mol Biol 41:9-13 (2011).

64 Du Y, Nomura Y, Luo N, Liu Z, Lee J-E, Khambay B et al., Molecular determinants on the insect sodium channel for the specific action of type II pyrethroid insecticides. Toxicol Appl Pharmacol 234:266-272 (2009).

65 Du Y, Nomura Y, Satar G, Hu Z, Nauen R, He SY et al., Molecular evidence for dual pyrethroid-receptor sites on a mosquito sodium channel. Proc Natl Acad Sci USA 110:11785-11790 (2013).

66 Burton MJ, Mellor IR, Duce IR, Davies TGE, Field LM and Williamson MS, Differential resistance of insect sodium channels with $k d r$ mutations to deltamethrin, permethrin and DDT. Insect Biochem Mol Biol 41:723-732 (2011).

67 Rinkevich FD, Su C, Lazo TA, Hawthorne DJ, Tingey WM, Naimov S et al., Multiple evolutionary origins of knockdown resistance $(k d r)$ in pyrethroidresistant Colorado potato beetle, Leptinotarsa decemlineata. Pestic Biochem Physiol 104:192-200 (2012).

68 Yu SJ, The Toxicology and Biochemistry of Insecticides, 2nd edn. CRC Press, Boca Raton, Florida (2014).

69 Valadez SK and Dehart BA, Terrestrial Field Dissipation of Phostebupirim (MAT 7484) on Minnesota Soil., 1994. https://archive.epa.gov/pesticides/ chemicalsearch/chemical/foia/web/pdf/129086/129086-015.pdf [20 May 2019].

70 Meinke L, Wangila D, Wright R, Hunt T, Peterson J and Kruger G, Corn rootworm management update, in 2018 Crop Production Clinic Proceedings, ed. by University of Nebraska-Lincoln Extension. University of Nebraska-Lincoln, Lincoln, NE, pp. 46-50 (2016).

71 Boetel MA, Fuller BW and Evenson PD, Emergence of adult northern and western corn rootworms (Coleoptera: Chrysomelidae) following reduced soil insecticide applications. J Econ Entomol 96:714-729 (2003). 
72 Hibbard BE, Meihls LN, Ellersieck MR and Onstad DW, Density-dependent and density-independent mortality of the western corn rootworm: impact on dose calculations of rootworm-resistant Bt corn. J Econ Entomol 103:77-84 (2010).

73 Elliott NC and Hein GL, Population dynamics of the western corn rootworm: formulation, validation, and analysis of a simulation model. Ecol Model 59:93122 (1991).

74 Onstad DW, Hibbard BE, Clark TL, Crowder DW and Carter KG, Analysis of density-dependent survival of Diabrotica (Coleoptera: Chrysomelidae) in cornfields. Environ Entomol 35:1272-1278 (2006).

75 Sparks TC and Nauen R, IRAC: mode of action classification and insecticide resistance management. Pestic Biochem Physiol 121:122-128 (2015). 